UDC $111+141$

LBC 87.1

\title{
THE PLACE OF SYMBOLIZATION IN THE PSYCHOANALYTIC MODEL OF THINKING: VERBAL AND PRE-VERBAL ASPECTS
}

\author{
Larisa V. Velikanova \\ Saint Petersburg, Russian Federation
}

\begin{abstract}
The article describes the process of symbol formation from the point of view of psychoanalytic theory. The author considers verbal and pre-verbal thinking and connects these two types with the process of symbol formation. The model of thinking proposed by W. Bion is taken as a foundation. The subject's ability to symbolize is characterized as inherent in a developed mental apparatus with a verbal type of thinking. Thinking is understood as the process of formation of mental elements from the processed somatic experience. Through the concept of object relations the author shows the difference in the functioning of thinking in a paranoid-schizoid and depressive position. The author introduces the concept of containerization and clarifies the difference between the mechanisms of normal and pathological projective identification, which the subject uses in a paranoid-schizoid position instead of repression. It is pointed out that the excessive use of pathological projective identification makes it impossible to develop thinking and symbol formation. The author defines the ability of the subject to endure frustration as the primary condition for the development of thinking. The secondary is the successful communication between a mother and an infant contributing to the infant's introjection of the maternal alpha function. This allows the mental apparatus to develop and makes it possible to acquire verbal thinking, to transit to a depressive position and to use symbols as products of mature symbol formation. The symbol is understood as a verbal form for somatic experiences, while the symbol does not have the characteristics of the original object. The author demonstrates, that in the early stages of development, the subject does not use the symbolization inherent in verbal thinking, but symbolic equalization, in which no distinction is made between the object and the symbol. Verbal thinking is considered as related to the acoustic remnants of words that are transmitted by the primary object due to the alpha function. In the early stages of development and in the case of a violation of symbol formation, subjects do not use symbols that are containers for somatic experiences, but pre-verbal and pre-symbolic elements. The author concludes that the process of symbolization underlies the development of the mental apparatus.
\end{abstract}

Key words: symbolization, thinking, Kleinian psychoanalysis, verbal thinking, symbolic forms, U. Bion, alpha function.

Citation. Velikanova L.V. The Place of Symbolization in the Psychoanalytic Model of Thinking: Verbal and Pre-Verbal Aspects. Logos et Praxis, 2021, vol. 20, no. 3, pp. 82-92. (in Russian). DOI: https://doi.org/10.15688/ lp.jvolsu.2021.3.9

УДК $111+141$

ББК 87.1

\section{МЕСТО СИМВОЛИЗАЦИИ \\ В ПСИХОАНАЛИТИЧЕСКОЙ МОДЕЛИ МЫШЛЕНИЯ: ВЕРБАЛЬНЫЙ И ДО-ВЕРБАЛЬНЫЙ АСПЕКТЫ}

\author{
Лариса Витальевна Великанова \\ г. Санкт-Петербург, Российская Федерация
}

Аннотация. В статье описывается процесс символообразования с точки зрения психоаналитической теории. Автор рассматривает вербальное и до-вербальное мышление и связывает их с процессом символообразования. За основу берется модель мышления, предложенная У. Бионом. Способность субъекта к сим- 
волизации характеризуется как присущая развитому психическому аппарату, обладающему вербальным типом мышления. Под мышлением понимается процесс образования психических элементов из переработанного соматического опыта. Через концепцию объектных отношений автор показывает различие в функционировании мышления на параноидно-шизоидной и депрессивной позиции. Автор вводит концепт контейнирования и проясняет различие между механизмами нормальной и патологической проективной идентификацией, которыми субъект пользуется на параноидно-шизоидной позиции вместо вытеснения. Указывается, что чрезмерное использование патологической проективной идентификации делает невозможным развитие мышления и символообразования. Первичным условием для развития мышления автор называет способность субъекта переносить фрустрацию. Вторичным является успешная коммуникация между матерью и младенцем, способствующая интроекции младенцем материнской альфа-функции. Это позволяет развиваться психическому аппарату и делает возможным обретение вербального мышления, переход на депрессивную позицию и использование символов как продуктов зрелого символообразования. Под символом понимается вербальная форма для соматических переживаний, при этом символ не обладает характеристиками изначального объекта. Автор показывает, что на ранних этапах развития субъект использует не символизацию, свойственную вербальному мышлению, а символическое уравнивание, при котором различия между объектом и символом не проводится. Вербальное мышление рассматривается как связанное с акустическими остатками слов, которые передаются первичным объектом благодаря альфа-функции. На ранних этапах развития и в случае нарушения символообразования субъекты используют не символы, являющиеся контейнерами для соматических переживаний, а до-вербальные и до-символические элементы. Автор делает вывод, что процесс символизации лежит в основании развития психического аппарата.

Ключевые слова: символизация, мышление, кляйнианский психоанализ, вербальное мышление, символические формы, У. Бион, альфа-функция.

Цитирование. Великанова Л. В. Место символизации в психоаналитической модели мышления: вербальный и до-вербальный аспекты // Logos et Praxis. - 2021. - Т. 20, № 3. - C. 82-92. - DOI: https://doi.org/ 10.15688/lp.jvolsu.2021.3.9

Вопрос о месте символа в процессе мышления поднимается в философии еще со времен античности, где Платон и неоплатоники занимались поиском возможности трансцендентных форм мышления. Позднее Кант проведет различение символа и схемы, Э. Кассирер введет понятие «символических форм» [Кассирер 2002], а К. Леви-Стросс [ЛевиСтросс 1985] сделает символ одним из ключевых понятий своей структурной антропологии, в центре которой будет стоять вопрос о вариациях усложнения мышления.

В психоанализе, начиная от Фрейда и заканчивая современной традицией, символизации отводится особое место. Она является процессом, лежащим в основании мышления. В каком-то смысле история психоанализа разворачивается из попытки Фрейда создать универсальный метод трактовки символов, лежащих в основании психического. Он начинает разговор о бессознательном с описания процесса символизации в «Толковании сновидений», и все дальнейшие разработки психоанализа будут опираться на концепцию «символического».

Современный психоанализ, как справедливо подчеркивает один из представителей бионианского направления Т. Огден, ставит перед собой вопрос о том, как мыслит субъект, а не о том, что он мыслит [Ogden 2010, 318] (курсив наш. - Л. В.). Таким образом, мы можем сказать, что современная психоаналитическая мысль интересуется не столько свойствами и характеристиками символа, сколько его ролью в функции и местом в структуре мышления [Ogden 2010; МаниКёрл 2008].

В данной статье мы производим попытку описания процесса символизации с точки зрения психоаналитической теории, а также определения его места в организации процесса мышления. Стоит сказать, что своей целью мы не ставим рассмотрение всех имеющихся на сегодняшний день психоаналитических концепций символизации, а ограничиваемся дискурсом одного из направлений британской психоаналитической школы - подходом У. Биона. Кроме того, ограниченность объема статьи не позволяет нам раскрыть полную картину возникновения и развития процесса символизации, поэтому в данном тексте мы осветим лишь один из аспектов и опишем символообразование, связанное с вербальным мышлением. 


\section{Телесные репрезентанты}

как основа психического

\section{в теории британского психоанализа:} истоки бионианской мысли

Концепция Биона интересна тем, что она переворачивает привычные представления о работе мышления. Мысль, по Биону, не является продуктом мышления, а предшествует ему. Мышление вторично по отношению к мыслям, оно возникает для того, чтобы справляться с ними. Бион говорит, что мышление это образование, вызванное давлением мыслей, а психопатологии всегда связаны с нарушением мышления и возникают по двум причинам: 1) в связи с нарушениями процесса образования мыслей; 2) в связи с нарушением аппарата, который «мыслит мысли». Мысли, согласно концепции Биона, являются модификациями телесных переживаний и усложняются по мере развития аппарата мышления [Бион 2008б].

Продолжая линию психоаналитического дуализма, Бион делает акцент на связи телесного и психического и говорит о том, что символизация выступает механизмом, позволяющим придать психическую форму телесным переживаниям. Процесс символизации лежит в основании образования психического аппарата и функции мышления. Корни идей Биона восходят к концепции телесности психики Фрейда [Фрейд 2008; Фрейд 2020] и теории М. Кляйн [Кляйн 2007], которая в своих работах указывает на наличие конституциональных факторов психического развития и их роль в формировании психических представлений.

Кляйн, говоря об устройстве психической реальности, вводит концепт «бессознательная фантазия», и эта идея позже будет развита ее последователями [Bronstein 2015; Айзекс 2001]. Можно сказать, что бессознательные фантазии являются психическими репрезентациями телесных ощущений, переводимыми во внутренний план. Влечения и соматические ощущения, которые переживает ребенок, воспринимаются им как наличие в его психической реальности объектов. Например, удовольствие от кормления или тепло материнского тела воспринимаются им как хорошие, удовлетворяющие объекты, обита- ющие в его реальности, а неудовольствие, вызванное отсутствием кормления или тепла, напротив, будут расцениваться как плохие объекты.

Особое внимание прояснению связи телесного и психического в контексте рассуждения о бессознательной фантазии уделила С. Айзекс - последовательница Кляйн, которая считала бессознательные фантазии первичными элементами психической структуры. Айзекс цитирует Фрейда: «мы представляем себе, что у своего предела оно (Ид) открыто соматическому, вбирая оттуда в себя инстинктивные потребности, которые находят в нем свое психологическое выражение...» и формулирует определение бессознательной фантазии: «с точки зрения современных авторов, это «психологическое выражение» инстинкта ${ }^{1}$ есть бессознательная фантазия. Фантазия (в первом приближении) - психическое следствие и представитель инстинкта. Нет влечения, нет инстинктивной потребности или реакции, которые бы не переживались в виде бессознательной фантазии» [Айзекс 2001, 153].

Из концепции бессознательной фантазии Кляйн развивает свою теорию частичных объектов, согласно которой младенец взаимодействует с парой противоположных по свойствам объектов - плохой и хорошей грудью. Термин «грудь» здесь равен понятию «мать» и указывает на функциональность отношений. В этот период раннего развития психика младенца подвержена расщеплению. Это значит, что для младенца на этом этапе развития еще не существует деления на внешнее и внутреннее, не существует целостных объектов, а кроме того, сильна тревога преследования и любые переживания являются чрезмерными по причине отсутствия функции символизации. Матери как целостного объекта на этом этапе для ребенка не существует, вместо нее младенец имеет дело с функциями матери, которые предстают в его реальности как хороший и плохой объекты. Этот период Кляйн, и вслед за ней Бион, называют параноидношизоидной позицией. В это время влечение к смерти особенно сильно, и младенец непрерывно подвергается страху аннигиляции (распада, уничтожения). Переживая собственные телесные неудовольствия как нападения плохих объектов, которые могут послужить его 
разрушению, младенец пытается избавить от них свою психику. Эти плохие объекты в его психической репрезентации являются одновременно внешними объектами и его субъективными соматическими переживаниями неудовольствия. Против этих фантазийных ${ }^{2}$ объектов он разворачивает оральные, анальные и уретральные атаки. Благодаря чему он, во-первых, может избавиться от неприятных соматических переживаний, а во-вторых, буквально нападает на эти объекты, используя доступные ему средства для телесной разрядки.

В терминах британского психоанализа этот процесс избавления от плохих объектов называется проективной идентификацией. Это незрелый защитный механизм психики, который позже преобразуется в вытеснение. Проективная идентификация позволяет выталкивать, эвакуировать из своей психики нежелательные элементы, в то время как вытеснение позволяет переместить их в область бессознательного.

Бион выделил 2 типа проективной идентификации: нормальную и патологическую [Бион 2010]. При нормальной проективной идентификации, которая используется всеми людьми в период раннего развития и служит для коммуникации, возможны и проекции и интроекции, то есть и «передача» психического материала и его «принятие», поэтому психика способна развиваться. Патологическая проективная идентификация развивается в ответ на неудовлетворение матерью потребностей ребенка и служит лишь для эвакуации элементов, и ее чрезмерное использование делает невозможным развитие мышления.

Для того чтобы прояснить этот момент, обратимся к модели мышления, предлагаемой Бионом.

\section{Психоаналитическая модель мышления \\ У. Биона}

Постулируя, что образование мыслей предшествует возникновению аппарата мышления, Бион отталкивается от тезиса, что в психической реальности младенца существует некое врожденное ожидание груди (как функции удовлетворения), которое он называет преконцепцией. Этот феномен можно сравнить с платоновскими эйдосами или понимать его как некую форму, ожидающую принятия содержимого. Бион говорит, что это врожденное ожидание, которое на физическом уровне мы можем наблюдать в форме сосательного рефлекса, возникает еще до столкновения младенца с удовлетворяющей грудью в опыте [Бион 2009].

Преконцепции, в свою очередь, соединяются с тем, чему Бион дает название «реализация», то есть с содержанием, которое может войти в форму. Реализация, таким образом, способствует удовлетворению потребности. Мы можем изобразить это положение бионовской модели в виде формулы: «преконщепиия + реализация $=$ удовлетворение». Удовлетворение, которое происходит одновременно на физическом, телесном и на психическом уровнях не может способствовать образованию мыслей [Бион 2008д].

Мысль, по Биону, рождается в моменты, когда удовлетворение не может быть достигнуто. Этот момент неудовлетворения называется негативной реализацией или отсутствием реализации, и он, так же как и любые ощущения, является объектом, то есть младенец сталкивается с объектом «нет-груди» или «минус реализация». Неудовлетворение (неудовольствие) рождает фрустрацию и только благодаря тому, что младенец может ее выносить, возникает мысль. Такую раннюю форму мысли Бион называет концепцией. Этот тезис можно изобразить в виде следующей формулы: «прекониепиия + негативная реализация = концепция» [Бион 2008д].

От способности младенца переносить фрустрацию, связанную с отсутствием объекта, зависит возможность образования мыслей, которые послужат материалом для строительства аппарата мышления и будут иметь степени усложнения по мере развития психики. Эти положения бионовской теории опираются на введенный Фрейдом «принцип удовольствия», роль которого в развитии мышления он описывает в своей статье «О двух принципах психического события». Фрейд говорит [Фрейд 2020, $13,32]$ о тенденциях психического аппарата, который на ранних стадиях подчинен принципу удовольствия и благодаря ему уклоняется от всего, что приносит неудовлетворение. Для концептуализации этого процесса Фрейд использует термин вытеснение, но необходимо при- 
нять во внимание, что в бионовской модели мы говорим о проективной идентификации как вариации замены вытеснению на ранних этапах психического развития ${ }^{3}$.

Младенец, неспособный справиться со своими переживаниями, с помощью механизма проективной идентификации выталкивает их из своей психики, распознавая как нежелательные элементы, приносящие неудовольствие, и помещает их в мать. Бион называет их бетаэлементами и определяет как сырой несимволизируемый материал чувственного опыта, пригодный только для эвакуации.

Здесь стоит ввести в наше рассуждение еще один важный концепт, изобретенный Бионом, и, лежащий в основании его подхода к практике [Бион 2008б; Бион 2009; Бион 2010]. [Сегал 1999; Segal 1957]. Мы не будем останавливаться на этом моменте подробнее и лишь скажем, что данная форма символообразования характеризуется своей конкретностью и неразличимостью между символом и вещью, которую он обозначает. Эта форма не является символизацией в том смысле, в каком этот термин использует Бион, то есть зрелой символизацией.

Процесс так называемой зрелой символизации зависит от обретения ребенком прочно установленной альфа-функции и перехода на следующий уровень психического функционирования - депрессивную позицию, где появляется возможность для вербального мышления, а также происходит трансформация первичного расщепления, благодаря чему появляется деление психики на сознательную и бессознательную части.

Отметим, что в кляйнианском дискурсе, в отличие от теории Фрейда, мы говорим о двух психических состояниях - о параноидно-шизоидной и депрессивной позициях. Эти позиции не являются фазами или стадиями психического развития, которые закреплены во времени, и изменения при переходах с одной позиции на другую не являются необратимыми. Это значит, что психика постоянно в процессе своего развития проходит последовательные циклы перемещений с параноидно-шизоидной на депрессивную позицию и наоборот.

Бион развивает мысль о сущности этих флуктуаций, подчеркивая их важность, при разработке своей «сетки» [Бион 2009]. Она представляет собой таблицу, по вертикальной оси которой расположены элементы психического опыта и вместе с тем уровни развития мышления. От более простого уровня, на котором субъект имеет в своем расположении лишь бета-элементы, таблица продвигается ко все более сложным и абстрактным системам элементов - научным системам и математическим вычислениям. Перемещение с одного уровня мышления на другой происходит благодаря циклическим флуктуациям между параноидно-шизоидной и депрессивной позицией. Бион называет этот момент трансформацией и указывает на необычайную болезненность этого перехода.

Главными характеристиками депрессивной позиции являются преодоление расщепления и появление целостности объектов. Хороший и плохой объекты, которые были двумя противоположными функциями матери, теперь объединяются. Происходит их интеграция, мать появляется как целостный объект, сочетающий в себе различные качества. Тревога преследования, всемогущество, спутанность и страх аннигиляции при переходе на депрессивную позицию ослабевают или исчезают, появляется переживание собственной отдельности от объекта и переживание границ своего «Я». В терминах философской антропологии мы можем сказать, что появляется ощущение эксцентричности, то есть возможность «фронтальной расположенности относительно окружающего поля» [Плеснер 2004, 253].

При этом возникают новые тревоги, младенец переживает чувство вины и скорби изза того, что ранее объект подвергался его атакам и теперь может быть нарушен или утрачен. Младенец начинает предпринимать попытки восстановления объекта, называемые в контексте данной теории репарацией, и проявляет заботу о любимом объекте. Кляйн считала, что этот процесс лежит в основании символообразования и в основании творческой способности человека, которые в свою очередь служат защитой от тревоги. Здесь же происходит усложнение психических механизмов, а также появляется способность отделения объекта от его функций и свойств. На депрессивной позиции появляется способность к зрелой символизации. Кроме того, 
отдельность от объекта открывает для психики новую перспективу: теперь становятся возможными отношения с объектами и образование между ними связей.

\section{Роль вербального мышления в процессе символообразования}

Как уже говорилось выше, Бион, развивая свою собственную теорию мышления, опирается на идеи Фрейда и Кляйн. Так, одной из важных разработок Фрейда, которой воспользовался в вопросе о сущности символизации Бион, является разнесение концептов вербального и предметного (образного) мышления. Фрейд уделяет внимание этому аспекту в работах по метапсихологии.

Так, в статье «Я и Оно» он выделяет два типа мышления - «мышление в образах» и «вербальное мышление». Первое он называет более древним и принадлежащим инстанции бессознательного, оно имеет дело с предметными репрезентациями (образами вещей), о втором говорит, что оно принадлежит инстанции предсознательного, которая хранит в себе словесные представления [Фрейд 2020, 14, 265-266]. «Эти словесные представления остатки воспоминаний, когда-то они были восприятиями и, как все остатки воспоминаний, могут снова становиться осознанными» [Фрейд 2020, 14, 264] и «происходят в основном от акустических восприятий, и этим, так сказать, определяется особое чувственное происхождение системы Псз (предсознательного. - Л. В.)... ведь слово, собственно говоря, - это остаток воспоминания об услышанном слове» [Фрейд 2020, 14, 265].

Развивая эту мысль в ключе бионовских идей, мы можем сказать, что возникновение вербального мышления связано с альфа-функцией матери. Мать, облекая в словесные репрезентации переживания ребенка, возвращает их ему с помощью речи. Таким образом она придает форму этим переживаниям и закрепляет за ними определенные значения. Хотя эти элементы еще не принадлежат зрелой символизации (поскольку ребенок еще не обладает своей собственной альфа-функцией), они, тем не менее, относятся к символообразованию, и мы можем назвать их до-символическими или до-вербальными.
Альфа-элементы являются материалом для сновидений, а также могут развиться в словесные репрезентации.

Отношения контейнера и контейнируемого, которые складываются между матерью и младенцем, являются первой простой до-вербальной коммуникацией. Способность матери выступать в виде контейнера, обладающего альфа-функцией, является ключевым моментом в развитии мышления. Именно здесь возникают первые факторы, ведущие к торможению развития или патологии мышления. Мать, неспособная принимать и перерабатывать психический материал ребенка, служит развитию у него формы патологической проективной идентификации [Бион 2008а]. Это можно описать следующим образом: младенец, испытывающий неудовольствие и тревогу, проецирует их в виде бета-элементов в мать, а она, будучи неспособной контейнировать их и превратить в альфа-элементы, отправляет их ребенку обратно в искаженном или непереработанном виде, усиливая его фрустрацию, которая теперь, в терминах Биона, превращается в «безымянный ужас». Тревога ребенка повышается до такого уровня, что он начинает с большой агрессией изгонять из себя нежелательные элементы, вместе с ними выталкивая и части своей психики (части «Я» и «Сверх-Я»), обедняя ее. Вместо интроекции материнской альфа-функции и использования ее для переработки психического материала происходит эвакуация, делающая невозможным дальнейшее развитие символообразования.

Мать, способная исполнять функции контейнера, способствует развитию нормальной проективной идентификации, включающей в себя цикл проекций и интроекций, и позволяет ребенку обрести альфа-функцию. Младенец интроецирует, перенимает материнскую функцию контейнера. Со временем он становится способным перерабатывать свои психические переживания с помощью обретенной альфа-функции, то есть превращать бета-элементы в альфа-элементы. Он начинает находить вербальные репрезентации для этих содержаний, и таким образом облекать переживания в форму-контейнер, в символ. Бион говорит, что символ служит контейнером для психических содержаний, но отношения контейне- 
ра и контейнируемого как прототип отношений ${ }^{4}$ появляется в психике лишь при наличии альфа-функции. В том случае, когда интроекции альфа-функции не происходит, субъект не способен осуществлять переработку своих бета-элементов, то есть наделять их символическими значениями, а затем облекать в слова. В этом случае он производит эвакуацию бета-элементов с помощью речи.

Иллюстрацией этого процесса может служить шизофренический бред, свидетельствующий о том, что субъект не способен придавать символическое значение собственным переживаниям. Он пользуется не символами, не языком, который в психоанализе рассматривается как символический порядок и служит для связи (коммуникации) между объектами (людьми), а подбирает слова, которые кажутся ему пригодными для выражения внутренних переживаний, но не понятны никому, кроме него самого.

\section{Соотношение вербального мышления и символизации в теории Биона}

Важно сказать, что для Биона символ это всегда продукт зрелой символизации, возможный лишь при наличии вербального мышления, которое, следуя его идеям, появляется как развитая форма мышления лишь при наличии альфа-функции и переходе на депрессивную позицию.

Бион уделяет вербализации большое значение почти во всех своих работах. В ранних статьях он использует термин «вербальное мышление» и акцентирует внимание на использовании языка в процессе мышления, приводя иллюстрации из анализа психотиков. Так, в статье о шизофреническом языке [Bion 2014 IV, 71-93] он описывает механизмы, задействованные в нарушениях символизации и мышления. Бион говорит здесь, что шизофреник использует язык тремя способами: язык может выступать как способ действия, способ коммуникации или средство мышления. Он подчеркивает, что шизофреник склонен производить действие там, где требуется мысль или слово, и напротив, при необходимости действовать он может прибегнуть к всемогуществу и заменять действие мыслью. При этом, даже пытаясь использовать язык как средство коммуникации, шизофреник будет обращаться не к зрелому символизму, а к его замене, то есть использовать слова как контейнеры для бета-элементов, не подвергая последние обработке. Можно сказать, таким образом, что у шизофреника отсутствует промежуточный этап в пользовании речью. Если не-психотик использует альфа-функцию, превращая свои переживания (бета-элементы) в то, что можно распознать, то есть символизирует, а затем помещает их в речь, то шизофреник будет использовать слова как контейнеры для бета-элементов.

Примером такого использования может послужить иллюстрация из работы М. Сешей, где она описывает использование языка шизофренической пациенткой. Эта девушка в момент психотического срыва для выражения своего ужаса от преследования использует слова «волк» и «полиция». Она оперирует произвольными элементами языка, эвакуируя в них с помощью механизма проективной идентификации бета-элементы. Она пользуется речью не для коммуникации, а для избавления от непереносимых психических содержаний, с помощью говорения она исторгает их из своей психики.

В статье «Заметки о теории шизофрении» [Bion 2014 VI, 73-84] Бион вновь подчеркивает важность достижения депрессивной позиции в развитии вербального мышления, делающего возможным зрелое символообразование. Он возвращается к этой мысли и при описании психотической личности: «...в своей статье для Международного конгресса в 1953 году я показал, что осознание психической реальности связано с развитием способности к вербальному мышлению, а формирование последней - с депрессивной позицией. Здесь я не буду об этом распространяться. Я отошлю вас к работе М. Кляйн "О важности формирования символа в развитии Эго”, а также к статье $\mathrm{X}$. Сигал, подготовленной для Британского психоаналитического общества. В своей статье Х. Сигал показывает важность формирования символа и раскрывает его связь с вербальным мышлением и компенсирующими драйвами, которые обычно относятся к депрессивной позиции» [Бион 2008г, 103]. В другом месте: «...поскольку вербальные мысли зависят от способности к интеграции, то совсем не удивительно, 
что их появление тесно связано с депрессивной позицией, которая, как считала Мелани Кляйн, является фазой активного синтеза и интеграции» [Bion 2014 VI, 76].

Это значит, что при переходе на депрессивную позицию субъект обнаруживает целостность объекта, то есть осознает, что частичные плохие и хорошие объекты теперь объединяются в один, с различными свойствами, а также обретает способность справляться с отсутствием объекта. Теперь оно ощущается не как неудовольствие, приобретающее конкретную форму в виде плохого объекта, а как собственно отсутствие, которое можно чем-то наполнить. С помощью вербального мышления субъект способен наделить отсутствие смыслом, значением, то есть осуществить символизацию. Он может осуществить работу альфа-функции, которую ранее для него выполняла его мать. Например, сформировать внутри себя мысль о том, что мать не исчезла безвозвратно и не бросила его, и, что неудовольствие, которое он переживает ввиду ее отсутствия, не будет длиться всегда и не угрожает его существованию.

В этой же статье Бион делает важное замечание, касающееся использования шизофрениками языковых элементов. Некоторые части речи шизофреник склонен использовать конкретно, так, существительное или глагол не символизируют собой вещи и действия, а являются таковыми: «сильное расщепление шизофреника делает для него затруднительным использование символов, а впоследствии существительных и глаголов» ${ }^{5}$ [Bion 2014 VI, 75]. Именно поэтому шизофреник может использовать действие там, где нужен глагол, и наоборот, прибегать к вербализации в момент, когда необходимо действовать. В статье «О галлюцинации» Бион добавляет [Бион 2008в, 123]: «...глаголы, описывающие восприятие посредством органов чувств, имеют двойной смысл для психотиков». Нарушение восприятия, которое связано с обработкой ощущений, принимаемых посредством органов чувств, искажает психическую реальность психотика и не дает возможности развиться зрелой символизации, которая зависит от трех факторов [Bion 2014 VI, 75-76]:

1. Способность воспринимать объекты целостными.
2. Отказ от расщепления, всемогущества и тревог, свойственных параноидно-шизоидной позиции.

3. Возможность объединить результаты расщепления, свойственного параноидно-шизоидной позиции, с новыми характеристиками, появляющимися на депрессивной позиции.

Последнее означает, что расщепление теперь приобретает новые свойства и становится расщеплением психики на инстанции сознания, предсознательного и бессознательного.

Здесь следует отметить, что, говоря о развитии вербального мышления, которое делает возможной символизацию, Бион предает переосмыслению идеи Фрейда. Напомним, последний считал, что в формировании вербального мышления главную роль играет инстанция предсознательного, которая, как мы помним из его метапсихологических работ, является латентной частью бессознательного (в описательном, но не топическом смысле), расположенного ближе к аппарату восприятиясознания.

В статье «Положение о двух принципах психического события» Фрейд пишет: «Первоначально мышление, по всей видимости, было бессознательным, поскольку оно поднялось над простым представлением и обратилось к отношениям между впечатлениями от объектов, и получило другие качества, воспринимаемые сознанием, только в результате соединения с остатками слов» [Фрейд 2020, $13,34]$. Бион же убежден, что первое, зачаточное мышление развивается не из остатков слов, воспринятых с помощью слуха, а благодаря зрительному восприятию. Однако развитие этого раннего мышления, по его мнению, возможно только при возможности использования младенцем нормальной проективной идентификации, включающей в себя циклы проекций и интроекций.

Цитируя Фрейда, в статье 1957 г. он вводит предположение, что раннее мышление (до-символическое и до-вербальное) связано не с акустическими остатками, а с «символами и зрением» [Бион 2008г, 103-104]. Ниже он называет эти визуальные элементы идеограммами.

Он пишет: «Теперь я считаю, что именно это мышление, которое 3. Фрейд описывал как обращенное к отношениям между объек- 
тными представлениями, ответственно за "сознание, связанное с чувственными впечатлениями". Меня укрепляет в таком мнении его утверждение, сделанное двенадцать лет спустя в статье “Эго и Ид”. В этой статье он говорит, что вопрос “Как нечто становится сознательным?” можно сформулировать более корректно: “Как нечто становится предсознательным?” Ответ может быть таким: “Посредством связывания предмета с относящимися к нему словесными образами". В своей статье 1953 года я говорил, что вербальное мышление тесно связано с осознанием психической реальности; это же я считаю верным также и для раннего до-вербального мышления, о котором я сейчас веду речь» [Бион 2008г, 104].

Таким образом, Бион отделяет зрелое мышление от раннего, зачаточного. Последнее связано со зрительными остатками восприятий и могут представлять собой в психической реальности ребенка овеществленные объекты, а зрелое - с остатками слов, то есть акустически воспринятых элементов. Мы полагаем, что элементы зачаточного мышления можно назвать бета-элементами и именно они являются, как видно из описаний сессий Биона с психотическими субъектами, элементами визуальных галлюцинаторных образов [Бион 2008в].

Выше мы говорили о важности вербализации матерью элементов, эвакуируемых в нее ребенком. В эти моменты ребенок еще не способен распознавать и запоминать символические значения, которые мать придает его переживаниям, но он интуитивно распознает ее настроение и отношение. Повторимся, что мать для него на этом этапе является не целостным объектом, а переживается функционально, то есть как плохой или хороший объект в зависимости от отношения, удовлетворения потребностей. Слова, которые она произносит, производя работу контейнера, не являются для него символами, но могут быть представленны в качестве хороших объектов, присутствующих в его реальности. Позже, когда он обретет способность к символизации, такая конкретность, выражающаяся в реальном присутствии объектов, станет ненужной, потому как все репрезентации переживаний найдут себя в качестве слов.

\section{Заключение}

Таким образом, мы можем говорить о символизации как о процессе, лежащем в основании способности мышления и делающем возможной коммуникацию между субъектами. Мы пришли к выводу, что символообразование начинает развиваться на самых ранних стадиях психического развития, а успешность этого процесса зависит от формирования первичной коммуникации матери и младенца. На первом этапе мать осуществляет символизацию вместо ребенка, наделяя его переживания символическими значениями с помощью вербализации. Говоря языком Биона, мать исполняет за него альфа-функцию, выступая перерабатывающим контейнером для до-символических содержаний. Успешное исполнение ею этой функции позволяет младенцу обрести собственную альфа-функцию, которая, в свою очередь, делает возможным развитие вербального мышления и, вместе с тем, способность к символизации. Кроме того, мы затронули тему различия вербального и до-вербального мышления и коротко осветили вопрос о мышлении шизофренического субъекта, которому вербальное мышление и символизация оказываются недоступными. Мы рассмотрели факторы, влияющие на сбой в развитии символизации и мышления, однако ввиду ограниченности объема статьи не уделили данной проблеме должного внимания. Вне поля зрения в данном тексте остался вопрос о различиях в процессах формирования психических патологий, связанных с невозможностью символизации и развития вербального мышления. Кроме того, в данном тексте мы не ставили перед собой задачу подробного рассмотрения до-вербального символообразования (незрелой символизации). Рассмотрение этих вопросов мы ставим перед собой целью для следующей статьи.

\section{ПРИМЕЧАНИЯ}

${ }^{1}$ Термин «инстинкт» встречается в некоторых вариантах переводов психоаналитических текстов и во избежание путаницы и физикалистского прочтения следует читать его как «влечение».

${ }^{2}$ В данном случае «фантазийный» следует понимать как принадлежащий бессознательной фан- 
тазии. Следует отметить, что термин «бессознательная фантазия» у Кляйн отличается от всех известных определений фантазии и в оригинальном языке эти два термина имеют различие на письме: «phantasy» вместо «fantasy».

${ }^{3}$ Предвосхищая идеи Кляйн, Фрейд в одном из примечаний к статье «О двух принципах одного психического события» пишет: «Я сочту это не как поправку, а как расширение рассматриваемой схемы, если для системы, живущей по принципу удовольствия, потребуются приспособления, с помощью которых она сможет избежать раздражителей реального мира. Эти приспособления - лишь «коррелят» вытеснения, которое обходится с внутренними неприятными раздражителями так, если бы они были внешними, то есть относит их к внешнему миру» [Фрейд 2020, 13, 33]. Одним из коррелятов вытеснения является «отбрасывание», совершаемое с помощью механизма проективной идентификации.

${ }^{4}$ Бион вместо термина «отношения» использует концепт «связь», который лежит в основании возможности объектов вступать в отношения друг с другом, а также участвует в процессе взаимодействия символов, которые вместе образуют символический порядок - язык. В основании этого концепта лежит идея (пре-концепция) о сексуальных отношениях родительской пары, отношениях рта и соска и отношениях между контейнером и контейнируемым. Мышление шизофреника отличается невозможностью формировать связи. Ввиду ограниченности объема данного текста мы не будем останавливаться здесь подробнее на прояснении этого вопроса.

5 Заметим, что существительные и глаголы являются частями речи, обозначающими вещи и действия.

\section{СПИСОК ЛИТЕРАТУРЫ}

Айзекс 2001 - Айзекс C. Природа и функция фантазии // Развитие в психоанализе. М.: Академ. проект, 2001. С. 121-190.

Бион 2008а - Бион У. Нападения на связь // Идеи У.Р.Биона в современной психоаналитической практике. М.: Русское психоаналитическое общество, 2008. С. 149-167.

Бион 20086 - Бион У.Р. Научение через опыт переживания. М.: Когито-Центр, 2008.

Бион 2008в - Бион У. О галлюцинации // Идеи У.Р. Биона в современной психоаналитической практике. М.: Русское психоаналитическое общество, 2008. С. 120-140.

Бион 2008г - Бион У. Отличие психотической личности от не-психотической // Идеи У.Р. Биона в современной психоаналитической практи- ке. М.: Русское психоаналитическое общество, 2008. С. 97-119.

Бион 2008д - Бион У. Теория Мышления // Идеи У.Р. Биона в современной психоаналитической практике. М.: Русское психоаналитическое общество, 2008. С. 168-179.

Бион 2009 - Бион У.Р. Элементы психоанализа. М.: Когито-Центр, 2009.

Бион 2010 - Бион У.Р. Внимание и интерпретация. СПб.: Восточно-Европейский институт психоанализа, 2010.

Кассирер 2002 - Кассирер Э. Философия символических форм. В 3 т. М.; СПб.: Унив. кн., 2002.

Кляйн 2007 - Кляйн М. Психоаналитические труды. B 7 т. Ижевск: ERGO, 2007.

Леви-Стросс 1985 - Леви-Стросс К. Структурная антропология. М.: Наука, 1985.

Мани-Кёрл 2008 - Мани-Кёрл Р. Когнитивное развитие // Журнал практической психологии и психоанализа. 2008. № 1. С. 56-83.

Плеснер 2004 - Плеснер X. Ступени органического и человек: Введение в философскую антропологию. М.: Рос. полит. энцикл., 2004.

Сегал 1999 - Сегал X. Функция сновидений // Современная теория сновидений. Назрань: АСТ; М.: Рефл-бук, 1999. С. 147-159.

Фрейд 2008 - Фрейд 3. Собрание сочинений. В 10 т. М.: Фирма СТД, 2008.

Фрейд 2020 - Фрейд 3. Собрание сочинений. В 26 т. СПб.: Восточно-Европейский Институт Психоанализа, 2020.

Bion 2014 - Bion W.R. The Complete the Work of W.R. Bion. In 16 Vols. L.: Karnac, 2014.

Bronstein 2015 - Bronstein C. Finding Unconscious Phantasy in the Session: Recognizing Form // The International Journal of Psychoanalysis. 2015. Vol. 96. Iss. 4. P. 925-944.

Ogden 2010 - Ogden T.H. On Three Forms of Thinking: Magical Thinking, Dream Thinking, and Transformative Thinking // The Psychoanalytic Quarterly. 2010. Vol. 79. Iss. 2. P. 317-347.

Segal 1957 - Segal H. Notes on Symbol Formation // The International Journal of Psychoanalysis. 1957. Vol. 38 (6). P. 391-397.

\section{REFERENCES}

Isaacs S., 2001. The Nature and Function of Phantasy. Razvitie v psihoanalize. Moscow, Akademicheskij Proekt Publ., pp. 121-190.

Bion W., 2008a. Attacks on Linking. Idei U.R. Biona v sovremennoj psihoanaliticheskoj praktike. Moscow, Russkoe psihoanaliticheskoe obshhestvo Publ., pp. 149-167. 
Bion W., 2008b. Learning from Experience. Moscow, Kogito-Centr Publ.

Bion W., 2008v. On Hallucination. Idei U.R. Bionav sovremennoj psihoanaliticheskoj praktike. Moscow, Russkoe psihoanaliticheskoe obshhestvo Publ., pp. 120-140.

Bion W., 2008g. Differentiation of the Psychotic from the Nonpsychotic Personalities. Idei U.R. Biona $v$ sovremennoj psihoanaliticheskoj praktike. Moscow, Russkoe psihoanaliticheskoe obshhestvo Publ., pp. 97-119.

Bion W., 2008d. A Theory of Thinking. Idei U.R. Biona $v$ sovremennoj psihoanaliticheskoj praktike. Moscow, Russkoe psihoanaliticheskoe obshhestvo Publ., pp. 168-179.

Bion W., 2009. Elements of Psycho-Analysis. Moscow, Kogito-Centr Publ.

Bion W., 2010. Attention and Interpretation. Saint Petersburg, Vostochno-Evropejskij institut psihoanaliza.

Cassirer E., 2002. The Philosophy of Symbolic Forms. Moscow, Saint Petersburg, Universitetskaja kniga Publ.

Klein M., 2007. Psychoanalytic Works. In 7 Vols. Izhevsk, ERGO Publ.

Levi-Strauss K., 1985. Structural Anthropology. Moscow, Nauka Publ.
Money-Kyrle R., Cognitive Development. Zhurnal Prakticheskoj Psihologii i Psihoanaliza, no. 1, pp. 56-83.

Plessner H., 2004. The Levels of Organic Life and the Human: Introduction to Philosophical Anthropology. Moscow, Rossijskaja politicheskaja jenciklopedija Publ.

Segal H., 1999. The function of dreams. Sovremennaja teorija snovidenij. Nazran, ACT Publ., Moscow, Refl-buk Publ., no. 1, pp. 147-159.

Freud S., 2008. The Complete the Work. In 10 Vols. Moscow, Firma STD Publ.

Freud S., 2020. The Complete the Work. In 26 Vols. Saint Petersburg, Vostochno-Evropejskij institut psihoanaliza.

Bion W.R., 2014. The Complete the Work of W.R. Bion. In 16 Vols. London, Karnac Publ., 2014.

Bronstein C., 2015. Finding Unconscious Phantasy in the Session: Recognizing Form. The International Journal of Psychoanalysis, 2015, vol. 96, iss. 4, pp. 925-944.

Ogden T.H., 2010. On Three Forms of Thinking: Magical Thinking, Dream Thinking, and Transformative Thinking. The Psychoanalytic Quarterly, 2010, vol. 79, iss. 2, pp. 317-347.

Segal H., 1957. Notes on Symbol Formation. The International Journal of Psychoanalysis, 1957, vol. 38 (6), pp. 391-397.

\section{Information About the Author}

Larisa V. Velikanova, Private Psychoanalyst, Master of Philosophy, Master of Psychology, Ruzovskaya St, 31, Office 407, Saint Petersburg, Russian Federation, laragiant@gmail.com, https://orcid.org/0000-0002-7265-6880

\section{Информация об авторе}

Лариса Витальевна Великанова, частнопрактикующий психоаналитик, магистр философии, магистр психологии, ул. Рузовская, 31, оф. 407, 190013 г. Санкт-Петербург, Российская Федерация, laragiant@gmail.com, https://orcid.org/0000-0002-7265-6880 